\title{
José Paúl y Angulo, Parlamentario
}

\section{JOAQUIN HERRAN PRIETO Universidad de Cádiz}

No resulta infrecuente el hecho de identificar a un personaje histórico exclusivamente con un solo acontecimiento, acaso determinante, pero no único de su vida. Se trata de un planteamiento de evidente simplicidad, pero del que se podrían aportar diversos ejemplos. Uno de ellos lo constituye la figura de José Paúl y Angulo, quien de manera casi automática queda unido al asesinato del general Prim. A pesar del largo proceso judicial a que dio lugar este suceso y de la abundante bibliografía generada por el magnicidio (del que, por lo mismo, no se van a ocupar estas páginas), sin embargo, la autoría o responsabilidad directa de Paúl y Angulo no ha podido quedar probada de una forma diáfana. Pero ello no ha sido obstáculo para que, desde 1870 ó 1871 , su nombre quedase indisolublemente enlazado con el homicidio de la madrileña calle del Turco.

No obstante, la biografía de José Paúl y Angulo presenta otras facetas de interés, las cuales apenas han sido tenidas en cuenta debido al eclipsamiento que sobre ellas producía el asesinato de Prim. Una de esas facetas es la de su actividad parlamentaria, de corta duración en el tiempo, pero muy útil para llegar al conocimiento completo de su ideologia, la cual, en buena medida, responde al planteamiento general desarrollado por el partido republicano a partir de la revolución de 1868. Es cierto que el propio Paúl se ocupó de proporcionar una versión más elaborada de su pensamiento en su obra Verdades revolucionarias, pero ello no resta importancia a este otro enfoque.

José Paúl y Angulo cuenta ya con un estudio biográfico, ciertamente mejorable y, al menos en lo que se refiere a sus años como diputado, resulta meramente descriptivo y presenta bastantes imprecisiones (1). Con todo, ello evita hacer un relato pormenorizado de su

(1) Cfr. Jesús de las Cuevas. Paúl y Angulo, Jerez de la Frontera, Caja de Ahorros de Jerez, 1987. 
vida, aunque, a modo de introducción que sirva para situar al personaje, sea conveniente exponer unas breves notas acerca de su biografía.

Nacio en Jerez de la Frontera, para unos en 1838 y para otros en 1842 (esta última fecha es la más aceptada), en el seno de una familia de desahogada economía, dedicada al negocio de la exportación de vinos. Gracias a esa situaciốn, recibió durante su juventud una esmerada educación, completada con varios viajes a Londres donde perfeccionaría sus conocimientos en el negocio vinatero al que, por tradición familiar, comenzó a dedicarse. En una de esas ocasiones en que se encontraba en la capital británica conoció al general Prim, exiliado en esta ciudad, donde preparaba la revolución que diera el traste con el reinado de Isabel II. Ambos trabaron pronto amistad, y Paúl y Angulo se comprometió a trabajar tanto política como económicamente en favor de la próxima revolución, para lo cual mantenía contactos en Cádiz con otros destacados revolucionarios, como Fermín Salvochea, Ramón de Cala o Rafael Guillén.

Uno de esos viajes a Londres, mitad de negocios y mitad conspiratorio, es aprovechado por Benito Pérez Galdós para realizar en uno de sus Episodios Nacionales una descripción física del jerezano: "Era [...] de estatura espigada, seco de carnes, tan acelerado y nervioso que no podía estar quieto en ninguna parte, expresivo en la mímica, suelto en la palabra, con acento andaluz de blando ceceo. Tapaba sus ojos con gafas azules; el rostro tenía curtido y picado de viruelas; el pelo al rape, la barba corta" (2).

Cuando en septiembre de 1868 estalle la revolución en Cádiz, José Paúl desempeñará un destacado papel en la misma. Por una parte, se coloca al frente de un grupo de paisanos armados que ha traído de Jerez con la finalidad de que el elemento popular no se quedase fuera del movimiento revolucionario que estaba teniendo lugar, evitando así que todo el protagonismo recayese en los militares pronunciados. Por otra parte, se encuentra su labor en la formación de varias juntas revolucionarias en la provincia de Cádiz. Así, es uno de los miembros que forman parte de la Junta Revolucionaria Provisional de Cádiz, que actuó en la capital gaditana durante unos días (3), tam-

(2) Benito Pérez Galdós, Episodios Nacionales. La de los tristes destinos. Madrid, Alianza, 1980, pp. 143-144.

(3) Cfr. Archivo Municipal de Cádiz, Actas y Documentos de la Junta Revoluctonaria Provisional de Cádiz, 18 de septiembre de 1868. 
bién estuvo presente en la Junta Local de Jerez y en la Junta Provisional de Cádiz (4). Igualmente, ejerció un activo papel en el establecimiento de la Junta Revolucionaria del Puerto de Santa Maria (5).

En las elecciones a Cortes generales celebradas tras el triunfo revolucionario, en enero de 1869 , se presentó como candidato en las filas del partido republicano por la circunscripción de Jerez de la Frontera, resultando elegido diputado por la misma, junto con los otros cuatro candidatos republicanos (6). Es uno de los últimos diputados en tomar posesión de su escaño, pues la Comisión de Actas del Congreso no examina la suya y le declara legalmente apto para ocupar su puesto hasta el 24 de marzo de 1869. Unos dias después tuvo lugar la discusión del dictamen de la citada Comisión de Actas y, al no pronunciarse nadie en contra del dictamen, quedó proclamado diputado (7).

De su primera etapa como representante en el Congreso de los Diputados, en el que no sobresalió precisamente como un gran orador, pueden destacarse tres aspectos: el primero de ellos, las buenas relaciones que mantenía con el general Prim, a quien incluso halagaba públicamente durante el desarrollo de las sesiones parlamentarias. En efecto, como consecuencia de aquella amistad trabada entre ambos meses atrás, Paúl declara en el hemiciclo: "tengo hacia el Sr. Ministro de la Guerra [Prim] el mismo afecto que un hijo pueda tener por su padre", a la vez que no duda en calificarle de "grande hombre" y "gran figura" (8). Relacionado con esto hay que situar el segundo de los aspectos destacables, su moderación verbal y su aceptación de las prácticas parlamentarias habituales. Así es, puesto que cuando en esta fase se dispone a iniciar un discurso o una intervención en el salón de sesiones se encomienda a la "benevolencia" de los diputados, afirma el gran respeto que le merecen los representantes democráticos que se sientan en el Congreso y acepta de buen grado y obedece las reco-

(4) Cfr. Archivo de la Diputación Provincial de Cádiz, Actas de la Junta de Gobierno de la Provincia de Câdiz, 10 de octubre de 1868.

(5) Cfr. Archivo Municipal del Puerto de Santa Maria, Actas de la Junta de Gobierno del Puerto de Santa Maria, 20 de septiembre de 1868.

(6) En la ciudad de Jerez obtuvo un total de 8.203 votos, mientras que en el conjunto de la circunscripción logró reunir 25.072 votos. Los otros cuatro candidatos republicanos elegidos en esta circunscripción fueron: Pedro Moreno Rodriguez, Eduardo Benot, Ramón de Cala y Rafael Guillén. Diario de Cádiz, 21 de enero de 1869 y La Republica Federal, 3 de febrero de 1869.

(7) Cfr. Diario de Sesiones de las Cortes Constituyentes (en adelante DSCO, 24 y 29 de marzo de 1869.

(8) Ibrdem, 3 de abril de 1869. 
mendaciones que le dirige el Presidente de la Cámara, dejando expresado claramente que su intención no es nunca faltar al orden. Incluso se aprecia en José Paúl un cierto grado de humildad en el modo correcto y casi sumiso con el que se dirige a los miembros del Gobierno y a la Presidencia del Congreso, y cuando él mismo reconoce lo escaso de sus dotes oratorias. En definitiva, muestra ahora un comportamiento y una forma de actuación personal que están muy lejos de la idea de hombre vehemente y violento con la que normalmente se le asocia. La tercera característica de esta etapa es la de su escasa participación en los debates del proyecto constitucional, aunque sí intervino en otros asuntos que en esos días se discutían en las Cortes. Pero, en relación con los artículos de la Constitución de 1869, tan sólo tomó la palabra una vez para hablar sobre la conveniencia de implantar la república en España (9).

En octubre de ese mismo año, como es sabido, tiene lugar la primera insurrección republicana organizada y extendida por buena parte de España. En ella, Paúl y Angulo tomó parte activa (como fue también el caso de otros diputados: Suñer y Capdevila, Ramón Castejón, Blas Pierrad...) y se puso al frente de una partida de hombres armados para intentar levantar a los pueblos de las serranías gaditana y malagueña en favor de la proclamación de la república federal. Junto a sus amigos Fermín Salvochea y Rafael Guillén anduvo varios dias entre continuas escaramuzas con el ejército, hasta que se vio obligado a buscar refugio en la cercana plaza de Gibraltar (10). Comenzó entonces su primer exilio, que transcurrió entre las ciudades de París y Ginebra, mientras que las Cortes condenaban políticamente la insurrección en unos términos altisonantes:

"No pueden ser Diputados los que han rasgado voluntaria y criminalmente su sagrada investidura; los que han provocado, acaudillado y favorecido una insurrección que ha conmovido a toda la sociedad, contra la cual parece principalmente dirigida, y en la que se han cometido crímines tan espantosos que recuerdan los tiempos de la más ruda barbarie y de la más repugnante feroci-

(9) Ibidem, 13 de mayo de 1869.

(10) Para un conocimiento algo más detallado de la participación de Paúl y Angulo en esta insurrección republicana, Vid. Joaquín Guichot, Historia General de Andalucía. Desde los tiempos mäs remotos basta 1870. Córdoba, Fundación "Paco Natera", 1982 (reedición), vol. II, 387-388. 
dad. No, no pueden, aunque lo intentaran saltando sobre los cadáveres de ciudadanos indefensos y tropezando con los escombros de los edificios incendiados, penetrar en el augusto templo de las leyes con la toga empapada en la sangre de los defensores de la sociedad y de la Constitución..." (11).

A raíz de estos acontecimientos, a las Cortes llegaron hasta cuatro suplicatorios distintos pidiendo autorización para procesar al diputado José Paúl y Angulo (12), pero no fue necesario conceder ninguno de ellos, puesto que poco después las mismas Cortes aprobaron una amnistía general para todos los "delitos políticos" cometidos en el país desde el triunfo de la revolución de septiembre, delitos entre los cuales, obviamente, estaba comprendida la insurrección republicana de 1869 (13). La amnistía permitió el regreso de Paúl, quien volvió a incorporarse a las labores del Congreso.

A partir de esta reincorporación, octubre de 1870 , comienza una segunda etapa en la actividad parlamentaria del diputado jerezano. Ahora sí, esta nueva etapa va a estar caracterizada por esas actitudes y formas que normalmente se identifican con este personaje. Desde entonces, sus relaciones con el general Prim estarán marcadas por un sentimiento que, más allá de las diferencias políticas o ideológicas, se acercará bastante al odio personal. Cierto que, en esta fase, los ataques de Paúl hacia Prim no se realizan durante las sesiones de Cortes, sino a través de los artículos que aparecen en el periodico que en Madrid dirigía Paúl y Angulo, El Combate. En él, los insultos y amenazas al general son constantes y, así, continuamente se alude a "la sangre del tirano", se le califica de "traidor" $o$, también refiriéndose a Prim, se afirma que habría que "matar[lo] en la calle como un perro" (14). En fin, es también muy conocida la amenaza que, al parecer, José Paúl le dirigió directamente a Prim en los pasillos del Congreso: "mi general, a cada cerdo le llega su San Martín". No son pocos los que aseguran que, además de las discrepancias políticas, entre ambos personajes existían también importantes diferencias de orden personal. Estas últimas serían, por una parte, el que Prim se negase a devolver a Paúl las cantidades de dinero que éste había adelantado para poner en

(11) DSCC, 13 de octubre de 1869, apéndice primero.

(12) Ibidem, 17 de febrero, 16 de marzo, 5 de mayo y 13 de mayo de 1870.

(13) La amnistía fue aprobada por las Cortes el 23 de junio de 1870 y promulgada por el Gobierno el 9 de agosto del mismo año.

(14) Cfr. Jesús de las Cuevas, Op. cit., pp. 77-83 y 91-95. 
marcha los preparativos de la revolución de $1868 \mathrm{y}$, por otra, una segunda negativa del Marqués de los Castillejos a su antiguo amigo: la de concederle, tal como le habría prometido, según parece, el cargo de embajador en alguna capital europea (15).

Como consecuencia del tono amenazante y violento del periódico y de los ataques personales que se realizaban desde El Combate (no sólo contra Prim, sino contra todo el Gobierno, contra la monarquía, contra las Cortes...) en el Congreso llueven los suplicatorios que piden autorización para procesar a Paúl. En total, entre el 15 y el 25 de diciembre, llegan veintidos suplicatorios en este sentido (16).

También es característico de esta fase el radicalismo en las formas por parte del diputado jerezano, radicalismo que se manifiesta en sus actitudes provocativas para con el resto de la Cámara y en su lenguaje grosero e insultante hacia los demás diputados. El incidente más importante provocado por las desconsideradas actitudes de Paúl y Angulo tuvo lugar en la sesión del 31 de octubre de 1870. Tras una discusión con el Presidente del Congreso, que no le concedía la palabra, Paúl, irritado, abandonó su asiento y, antes de salir del hemiciclo, se cubrió la cabeza con su sombrero, lo que, para los diputados de 1870 , era una grave falta de respeto hacia la institución que ellos representaban. Y, lejos de calmar los ánimos, con sus explicaciones sobre el incidente volvió a provocar la reacción airada de los diputados (17).

En cuanto a su vehemencia verbal, igualmente es posible aportar algunos ejemplos que demuestran la rápida evolución que en este aspecto experimentó la personalidad de José Paúl en un corto periodo de tiempo. Si, en el período anterior a su primer exilio, al comenzar a hablar a la Cámara mostraba su respeto y reconocimiento por los representantes de la soberanía nacional que se sentaban junto a él y aparecía humilde y comedido, ahora no vacila en calificar a los diputados no republicanos de "tiranuelos" y sus actos de "indignos". A la vez, afirma que las Cortes han dejado de representar a la soberanía nacional debido a que están reunidas "por los medios que todos conocemos", lo que a él, a la hora de hablar ante los demás diputados, le produce "repugnancia". Y, casi a manera de conclusión de su pensamiento en este sentido, resume que las actuaciones del Congreso no

(15) Cfr. Francisco Pi y Margall y Francisco Pi y Arsuaga, Historia de España en el siglo XIX. Barcelona, Miguel Segui, editor, 1902, t. IV, p. 562.

(16) DSCC, 15 y 24 de diciembre de 1870.

(17) Ibidem, 31 de octubre de 1870. 
son más que una "farsa indigna", lo que vuelve a excitar sobremanera los ánimos de los diputados. Por supuesto, esta forma de expresarse le supuso, no sólo la reprobación de la mayoría de la Cámara, sino también un continuo enfrentamiento con su Presidente, quien reiteradamente le llamaba al orden y exigía que respetase las buenas formas parlamentarias, advertencias que Paúl y Angulo no tenía en cuenta en absoluto (18).

Pero estas actuaciones no le valieron sólo el enfrentamiento con los diputados no republicanos, sino que, a partir de entonces, comienzan a detectarse diferencias entre Paúl y sus propios correligionarios. Estas diferencias están basadas en el hecho de que José Paúl, evidentemente favorable a la instalación de la república, se mostraba partidario de traer este sistema de gobierno a España por el medio que fuese. Si no se había conseguido instaurar la república por medios pacíficos (elecciones), ni mediante el levantamiento de partidas republicanas organizadas (la insurrección de octubre de 1869 en la que él mismo tomó parte activa), entonces había que intentarlo, en su opinión, a través de un levantamiento general del pueblo español que diese al traste definitivamente con el sistema monárquico, tal como se reflejaba en la Constitución de 1869. Por ello, dice que si el sistema de gobierno de España se plantea en términos de fuerza, él está convencido de que el pueblo hará "lo que deba" (19), en clara referencia a su creencia de que, antes o después, se producirá el levantamiento popular que instaure la república.

Sin embargo, la mayor parte de sus compañeros de partido que se sentaban con él en el Congreso, era partidaria de una actuación más moderada o contemporizadora. También, claro está, abogaban por la instalación de la república, pero de modo pacífico, por lo que no estaban dispuestos, ni mucho menos, a arriesgarse a un descabellado levantamiento general que podía acarrear bastantes más consecuencias negativas que positivas para el partido republicano. Baste recordar ahora la moderación que siempre mostraron algunos de los más destacados dirigentes republicanos, como Estanislao Figueras, Francisco Pi y Margall o Emilio Castelar.

Teniendo en cuenta estas diferencias, resulta más fácil comprender los velados ataques que lanzaba entonces Paúl y Angulo contra sus propios correligionarios y el escaso apoyo que a veces demostraban éstos cuando, mediante una votación, habia que respaldar a su

(18) Ibidem, 31 de octubre y 15 y 16 de diciembre de 1870.

(19) Ibridem, 31 de octubre de 1870. 
compañero. Así, Paúl, en las otras veces citada sesión del 31 de octubre de 1870 , refiriéndose a la labor que él como diputado debía desempeñar en el Congreso, afirmó que:

“... debo cumplir con ese deber [exponer los verdaderos deseos del pueblo], tanto más imperioso, cuanto que mis correligionarios, compañeros de diputación, no han cumplido con él de una manera satisfactoria a mi entender".

Y, haciendo alusión a la tarea que, en su opinión, debía realizar en esos momentos el partido republicano, como la de organizar a las masas con vista a ese levantamiento popular, argumentaba asi:

"Porque si el partido republicano, que se compone de los hombres de más energía del pueblo español, y hablo del partido en general, no de sus representantes aquí, no ha organizado hasta ahora sus huestes convenientemente para enseñaros que hasta en el terreno de la fuerza somos más que vosotros [la mayoría monárquical; si el partido republicano no ha hecho esto hasta ahora, ha dependido del carácter, de los instintos, de los sentimientos de algunos de sus jefes".

La respuesta de sus compañeros diputados vino, también en esa sesión, a la hora de apoyar con los votos la proposición que había presentado Paúl y Angulo, que en esos momentos se debatía, y que mostraba claramente el distanciamiento existente entre los republicanos más radicales y el resto de su grupo. En efecto, Paúl sólo obtuvo el respaldo en forma de votos, aparte del suyo propio, de cuatro de sus compañeros, significados radicales: Ramón de Cala, Fernando Garrido, Francisco García López y Francisco Suñer y Capdevila (20).

Como es de sobra conocido, a finales de diciembre de 1870 tuvo lugar el atentado que acabaría con la vida de Juan Prim, y del que se inculpó como principal sospechoso a José Paúl y Angulo, lo que le obligó nuevamente a marchar al exilio, esta vez de forma definitiva, por lo que en esa fecha acabó su breve actividad como parlamentario. Su vida durante este segundo exilio, período bastante desconocido, transcurrió por varias ciudades americanas, Montevideo, Buenos Aires, Nueva York, y europeas, Londres y París. Ni siquiera pudo regresar a España cuando se proclamó la república en 1873, por la que él tanto había combatido. La muerte le sobrevino en Paris en abril de 1892.

(20) Ibidem, 31 de octubre de 1870. 
Un análisis detallado de sus distintas intervenciones en el Congreso de los Diputados entre 1869 y 1870 , podría dividir estas intervenciones situando, en primer lugar, su participación en los distintos debates que se suscitan en la Cámara durante este período y, en segundo lugar, su labor de lo que hoy se llamaría, utilizando el lenguaje parlamentario, control del ejecutivo, es decir, el planteamiento de preguntas o interpelaciones al Gobierno. Desde el punto de vista ideológico, claro está que reviste más importancia e interés su participación en los debates de la Cámara, que se concretan en las intervenciones del 3 de abril de 1869, acerca de la situación política en Andalucía en general, y en Jerez en particular; en la del 13 de mayo de 1869 , dentro del debate del proyecto constitucional, en el que José Paúl plantea una enmienda al artículo 33; y en la del 31 de octubre de 1870 , sesión conflictiva en la que propone que, antes de continuar las sesiones de Cortes, los diputados sean ratificados mediante una votación en sus respectivas circunscripciones electorales. Se podría añadir en este apartado su intervención en las sesiones de los días 15 y 16 de diciembre de 1870 en las que toma la palabra, en principio, de forma incidental para señalar diversas irregularidades que él cree observar en las autoridades judiciales con respecto al periódico que dirige en Madrid, el citado El Combate, pero que termina por convertirse en un alegato en contra de las mismas Cortes de las que él forma parte.

La primera de esas intervenciones, como ya se ha señalado, tuvo lugar el 3 de abril de 1869 (21), enmarcada en el debate acerca de los sucesos o insurrecciones ocurridas en Andalucía, especialmente en las ciudades de Cádiz, Málaga y Jerez, entre los meses de diciembre de 1868 y marzo de 1869. En concreto, los sucesos de Jerez se originaron a mediados del mes de marzo, cuando grupos de ciudadanos se lanzaron a las calles, formaron barricadas y se enfrentaron con el ejército para exigir la abolición de las quintas, dando lugar a un número no bien determinado de muertos y detenidos (22).

El hecho específico que motiva el discurso de Paúl se refiere a uno de los episodios, dramáticos, de esa insurrección popular: él afirma haber visto personalmente por las calles de Jerez a un soldado borracho que llevaba sobre sus hombros a un niño ensagrentado y muerto, siendo muy probable que su muerte hubiese sido causada por el mismo soldado que lo portaba. Este suceso luctuoso le da pie para

(21) Ibúdem, 3 de abril de 1869.

(22) Estos sucesos pueden seguirse con detalle en Diario de Câdiz, 16-21 de marzo de 1869. Jesús de las Cuevas ofrece un tesumen de los mismos en $O P$. cit., pp. $41-43$. 
exponer por primera vez en el Congreso una de sus principales ideas: el antimilitarismo. El soldado, por el mero hecho de serlo, puede convertirse muy făcilmente en una máquina de matar:

"si la casaca militar no puede evitar que bajo de ella se abrigue un corazón infame, tal vez podría creerse que precisamente la casaca militar puede ser causa, en algún tanto, de que se abrigue. Porque el hombre a quien se coloca bajo la tutela del capitán, el hombre a quien se le hace marchar como una máquina, el hombre a quien se le obliga a matar cuando se le manda a hacer fuego, a ese hombre se le despiertan naturalmente ideas más sanguinarias que a cualquier otro ciudadano; porque el soldado tiene, por desgracia, un solo momento de autonomía en su vida militar, que es el momento de la victoria, que suele ser también el momento del saqueo."

Para Paúl y Angulo, la responsabilidad de la insurrección jerezana recae directamente en el Ayuntamiento progresista de la ciudad, que desempeña el gobierno local llevando a la práctica unas medidas que van en contra de los intereses mayoritarios de la población, claramente favorables a la república, como quedó demostrado en las pasadas elecciones. En especial, hace recaer las culpas en el alcalde Pedro López Ruiz, personaje que ha desarrollado un importante papel en la provincia de Cádiz en los momentos posteriores al triunfo revolucionario, pero que en absoluto es aceptado en Jerez y que, según Paúl, fue el primero que ordenó hacer fuego contra los ciudadanos insurrectos. Añade, además, una idea interesante acerca de la forma en que el mencionado López Ruiz pudo conseguir su acta de cocejal en las elecciones municipales y, con posterioridad, ser designado alcalde:

"sólo pudo Don Pedro López Ruiz formar parte del ayuntamiento por haberse dividido la población en trece colegios electorales, lo cual hizo que los colegios fueran muy pequeños, y permitió que un grupo de progresistas pudiese votar a dicho López Ruiz."

Es decir, pone de manifiesto cómo desde los mismos comienzos de la revolución de 1868 , al menos en la provincia de Cádiz, empieza a utilizarse un peculiar modo de corrupción del proceso electoral, el conocido como sistema gerrymandering, importado de los Estados Unidos, donde se había convertido en una práctica bastante habitual (23).

(23) En la actualidad preparo un estudio sobre la práctica del sistema gerrymandering, aplicado a las elecciones celebradas en la provincia de Cádjz a partir de la revolución de 1868. Se trata de un sistema muy poco estudiado en España, pero que en los países anglosajones, especialmente en los Estados Unidos, de donde es originario, cuenta ya con una bibliografia amplísima. 
Pero la exposición de los acontecimientos ocurridos en Jerez es lo que va a servir a Paúl para enlazar con otra de sus ideas fundamentales, la que ya en aquellos momentos se conocía como la "traición" a la revolución (Paúl, empleando un lenguaje más popular, afirmaba que la revolución se había convertido en "un camelo a la Nación"). Según este argumento, "los hombres del Poder ejecutivo son moralmente responsables de la sangre derramada en Cádiz, en Málaga y en Jerez", puesto que, gobernando en contra de los intereses de la mayoría del pueblo español, en opinión de Paúl y Angulo, no han dejado más opción a ese pueblo que oponerse con las armas en la mano a las arbitrarias decisiones gubernamentales. No obstante, Paúl todavía se encuentra en el período que podría calificarse como "moderado" en cuanto a su forma de actuar y expresar sus ideas, por lo que ofrece al Gobierno una solución para remediar esa traición a la revolución y que la misma no termine por convertirse en un "río de sangre" y un "cúmulo de horrores". La solución no es otra que la de volver a la "vía verdaderamente revolucionaria", 10 que, en la práctica, venía a significar tan sólo aceptar y aplicar los principios e ideas proclamadas por el partido republicano, algo que, evidentemente, no estaba en el ánimo del grupo mayoritario de las Cortes.

Termina esta intervención del diputado jerezano con la expresión de otra idea de interés. Era muy común en esos momentos identificar los intereses de las clases populares o desfavorecidas con el partido republicano, cuyos componentes también pertenecerían a dichas clases populares, mientras que los monárquicos y progresistas estaban identificados con la clase burguesa, cuyos intereses defendían. Sin embargo, Paúl y Angulo quiere dejar bien claro que no ha de existir de forma necesaria una contraposición o enfrentamiento entre el partido republicano y la clase burguesa. Esta idea exponía una verdad, ya que una buena parte del apoyo electoral de los republicanos provenía precisamente de la burguesía pequeña y media, pero así mismo estaba Paúl interesado en que esa idea quedase expuesta con claridad, atendiendo a su situación personal, puesto que él pertenecía a una familia de esa clase burguesa, enriquecida con el negocio de exportación de vinos y, con todo, defendía los puntos de vista del partido republicano.

"para que el país sepa lo lejos que está S.S. [el Ministro de la Gobernaciónl del camino de la verdad, diré que los republicanos de esa feroz provincia de Cádiz han elegido como representante al primer contribuyente de Cádiz. Ya ve S.S. cuán falsa es la idea que quiere despertar de que el partido republicano está enteramente separado, enteramente divorciado, de la clase rica." 
Su segunda intervención importante en el Congreso se produjo en el mes de mayo de 1869 con motivo de los debates del proyecto constitucional. Es la única vez que toma la palabra para opinar en este debate, y lo hace cuando se discute uno de los artículos más polémicos de la futura Constitución, el artículo 33, que hacía referencia a la forma de gobierno que habría de adoptar el país (24). El proyecto constitucional determinaba que esa forma de gobierno sería la monarquía, pero el partido republicano intentó (sin éxito) por medio de la presentación de varias enmiendas que el citado artículo quedase finalmente redactado en unos términos más cercanos a sus tesis políticas. La enmienda de Paúl y Angulo pedía que el artículo 33 del proyecto fuera redactado en la forma siguiente:

"La Nación española se gobierna por sí misma y delega el poder ejecutivo en un directorio de cinco individuos, que será nombrado por las Cortes cada tres años."

En la explicación de su enmienda, José Paúl repite la idea que antes se ha llamado la traición a la revolución, pues el período de verdadera libertad alcanzado con el triunfo de septiembre de 1868 y culminado con el periodo de actuación de las Juntas revolucionarias (que él califica de "periodo sublime" y "período grandioso") ha sido traicionado por el Gobierno y por la mayoría monárquica de la Asamblea que, con las medidas adoptadas por ellos, no han buscado el bienestar del pueblo, sino tan sólo el suyo propio.

"¿Dónde está la causa Sres. Diputados, dónde está la causa de que la gran aceptación universal de que gozaba la revolución de Septiembre haya desaparecido? Yo creo que es fácil encontrarla. La causa de ese descrédito de la revolución de septiembre, la causa de que no goce hoy de la misma aceptación que en los primeros momentos, hay que buscarla en los actos del Gobierno provisional, hay que buscarla en los actos del Poder ejecutivo, hay que buscarla en los actos de esta Asamblea, hay que buscarla en ese dualismo que los hombres de la unión liberal, los hombres del partido progresista y los hombres del partido democrático-monárquico han introducido entre el pueblo y los gobernantes, entre el pueblo y el círculo gubernamental, del que

(24) DSCC, 13 de mayo de 1869. 
ellos y sólo ellos se han apoderado, como si fuesen los verdaderos, los únicos representantes de la revolución de Septiembre."

Esos actos a los que se refería Paúl eran, entre otros, la exclusión de los republicanos del Gobierno Provisional, el manifiesto monárquico dado poco después por el mismo, la sangrienta represión de las insurrecciones andaluzas, la ley que llamaba a filas a 25.000 hombres, o la autorización de los estados de sitio. En la interpretación de Paúl y Angulo, la monarquía que se pretende sancionar no se puede entender sin sus tres apoyos básicos: "la Iglesia, la influencia de la empleomanía y el militarismo." Pero la Iglesia, paradigma del antiprogreso y esencialmente antiliberal, la burocracia o funcionariado sobre el cual el gobierno puede desarrollar su "influencia moral", y el militarismo como apoyo de la monarquía por medio de la fuerza, son por completo contrarios a los intereses y aspiraciones del pueblo. Si se acepta, además, otra de las tesis que defiende: "el pueblo en las ciudades más pupulosas de España, en las principales capitales, pide la forma republicana", entonces queda muy claro el conflicto de intereses que se está produciendo: el Gobierno y el Congreso están actuando en contra de las esperanzas populares.

A partir de ese momento, su argumentación se sitúa entre la advertencia y el catastrofismo. Si no se acepta de manera pacífica el sistema republicano, para el cual el pueblo español está perfectamente preparado, entonces ese mismo pueblo tratará de alcanzarlo por medio de la fuerza. Por lo tanto, o se admite la república (en la forma de Directorio que él propone, o en cualquier otra), o "ahora o dentro de poco seguramente, el pueblo se batiră", lo que podía sonar a vaticinio de la posterior insurrección de octubre de ese mismo año. En definitiva, trataba de presentar a la república como garantía de la paz en España, mientras que la monarquía sería equivalente a enfrentamiento armado en el país. No obstante, ni el tono catastrofista, ni la amenaza que se traslucía en sus palabras movieron a las Cortes a aceptar la enmienda propuesta por Paúl.

Sus siguientes intervenciones se producen ya dentro del período de pleno radicalismo ideológico y personal. Así, cuando el Congreso va a reanudar sus sesiones después del descanso de las vacaciones veraniegas de 1870 , presenta la siguiente proposición (25):

(25) Ibidem, 31 de octubre de 1870. 
"Pedimos a las Cortes se sirvan acordar que antes de reanudar sus tareas en la ocasión presente, se proceda a la confirmación de los poderes otorgados a cada uno de sus miembros por las respectivas circunscripciones electorales."

Se trata de una proposicion que defendió por medio de un lenguaje violento y en medio de las continuas llamadas al orden del Presidente de la Cámara. Incluso, como se indicó con anterioridad, con esta intervención, no sólo atacaba a la mayoría gubernamental, sino que también sus propios compañeros de partido eran objeto de sus críticas, ya que, en su opinión, no se habían sabido defender lo suficientemente bien los fines para los cuales se sentaban en los bancos de las Cortes. La misma tensión que se desprende de este discurso y la no muy elevada capacidad oratoria de Paúl, hacen que la exposición sea en algunos momentos reiterativa y no muy clara.

Pero, en síntesis, su argumentación podría resumirse del modo siguiente: el Parlamento que en esos momentos se halla reunido es ilegal por dos motivos. En primer lugar, porque "estas Cortes Constituyentes [...] están aquí reunidas por los medios que todos conocemos", es decir, gracias a la corrupción de las propias elecciones (es la primera vez que Paúl y Angulo afirma que las elecciones legislativas de enero de 1869 fueron manipuladas por el Gobierno provisional). Y, en segundo lugar, también son ilegales porque "las Cortes Constituyentes proclamaron su propia soberanía; es decir, desconocieron y negaron la soberanía del pueblo". Si las Cortes son ilegales y "se han olvidado de que el hombre público se debe a su país y no a miras bastardas", esto supone que el Gobierno que actúa de acuerdo con ellas se ha convertido en una "dictadura hipócrita", una "dictadura fatal, cubierta con la capa de constitucionalismo". Así pues, en el Parlamento no se hace más que representar una "farsa indigna", que corre el riesgo de enfrentarse a "200.000 corazones de bravos ciudadanos dispuestos a morir."

Sin embargo, hay un modo de evitar este final catastrófico: que se acepte su proposición de ratificar a los diputados en sus respectivas cincuscripciones, lo que, en la práctica, equivalía a celebrar nuevas elecciones legislativas. En la creencia de Paúl y Angulo, esas nuevas elecciones arrojarían una mayoría republicana que reconciliaría al Parlamento con la ciudadanía, pero su proposición no obtuvo ni siquiera el apoyo de sus propios correligionarios (sólo votaron a favor de la misma cuatro de sus compañeros, además de él), falta de apoyo en la que, sin duda, debió influir el modo grosero e inconveniente de la exposición de su idea. 
Su última intervención en el Congreso de los Diputados ocurrió a mediados de diciembre de 1870, pocos días antes del atentado contra el general Prim (26). En principio, usa de la palabra por alusiones, ya que tanto él como el periódico que dirige, El Combate, han sido mencionados por otro orador. En esta su última intervención, niega que en España exista libertad de imprenta, aseveración que intenta demostrar con el ejemplo de su periódico, el cual es con frecuencia recogido por los agentes de la autoridad muy poco tiempo después de ser puesto a la venta. Según Paúl y Angulo, la recogida de su periódico estâ determinada incluso mucho antes de que comience a imprimirse, de donde deduce que el Gobierno utiliza al poder judicial (que es el que da la orden material de la recogida de los ejemplares) para acabar con la libertad de imprenta, por lo que ese mismo poder judicial ha terminado por convertirse en un "humilde servidor de un Gobierno despótico."

El centro de sus ataques, en esta ocasión, es el Ministro de la Gobernación, Nicolás María Rivero, quien también ha sido atacado con dureza en el periódico de Paúl, causa que, a su juicio, motiva en buena parte la actuación del Ministro. En otras palabras, la recogida de los ejemplares de $E l$ Combate podría ser una venganza del mismo Gobierno. Termina su discurso nuevamente haciendo referencia a "la indigna farsa que aquí [en las Cortes] se representa", términos que en esta ocasión alteran y exaltan los ánimos de los diputados, varios de los cuales piden que se tome nota literal de los mismos para, en la siguiente sesión, pedirle a José Paúl explicación acerca de ellos, pues habían puesto en entredicho el honor de la Cámara.

En efecto, un día después, el Presidente pide a Paúl que explique al resto de los diputados aquellas palabras "tan duras y tan inconvenientes". La defensa que adopta el jerezano es bastante comprensible en esta ocasión: días atrás, en otro discurso pronunciado por él mismo, ya había expuesto la misma idea y utilizado las mismas palabras ("farsa indigna") para referirse a las labores desarrolladas en el Congreso, pero entonces nadie se alteró ni se le pidieron más explicaciones, por lo que no entiende el motivo por el cual se le exigen en ese momento. De todas formas, ofrece una doble explicación de lo que él ha querido dar a entender con esa expresión. Por una parte:

"al hablar yo de farsa, y de farsa indigna, quería decir que mientras el pueblo sufre inquietud atroz, mientras el pueblo sufre

(26) Ibr̈dem, 15 y 16 de diciembre de 1870 . 
miseria y hambre por estar mal gobernado, muy mal gobernado, los Sres. Diputados se olvidan del santo deber que les impone el mandato que del pueblo han recibido."

Y, por otra parte, también entiende como farsa, "el hecho político de darse leyes en nombre de la soberanía nacional, cuando tal soberanía es un mito", todo lo cual enlazaba directamente con su concepto de que las Cortes allí reunidas eran ilegales, por lo que él creía justificado el uso de la expresión "farsa indigna" y no veía motivo alguno para retirarla. Concluyó la intervención afirmándolo así:

"no ha sido mi objeto ofenderlos [a los diputados] personalmente; pero la idea política que en esa palabra se encierra, no puedo retirarla. Es cuanto tenía que decir."

Así fue: era cuanto tenía que decir, por lo que no volvió a intervenir en las sesiones parlamentarias en los pocos días que aún le restaban de residencia en España. Es probable, incluso, que se fuese alejando cada vez más de sus propios compañeros de partido, la mayoría de los cuales que se sentaban con él en el Parlamento no estaban por la línea radical propugnada por José Paúl y Angulo.

Se puede hacer referencia, finalmente, a esa labor que hoy se llamaria "control del ejecutivo", trabajo que se lleva a cabo mediante la realización de preguntas al Gobierno por parte de la oposición. En esta labor de control, Paúl se muestra en especial interesado por la moral de la propia Administración, tal como lo demuestra el hecho de que sus preguntas van dirigidas a poner en conocimiento del Gobierno lo que, en la actualidad, se denominarían casos de incompatibilidad. Por ello, denuncia el caso de dos jueces que ejercen en Jerez de la Frontera, población en la que, además, tienen varias propiedades, razón que, de ser cierta, los inhabilitaría para desempeñar su cargo. Igualmente, expone el hecho de que un número elevado de diputados son, a la vez, funcionarios de la Administración, lo que, a su juicio, les impediría, por falta material de tiempo, dedicarse a las dos ocupaciones, situación que también se convertiría en ilegal si se aplicase el artículo 59 de la Constitución. A este respecto, añadía Paúl: "No es que a mí me interese gran cosa la aplicación de la Constitución en general, pero sí en este punto de decencia y de decoro", lo que trasluce ese interés suyo por la existencia de una cierta moralidad en la Administración pública (27).

(27) Ibidem, 31 de marzo, 8 de mayo y 12 de julio de 1869 . 
Esta sería la actividad parlamentaria de José Paúl y Angulo, un tipo de diputado poco frecuente, aun incluso en el marco del turbulento período del Sexenio Revolucionario español, un diputado mucho más interesado en la acción o puesta en práctica de sus ideas que en la labor teórica de exponer las mismas. Tal vez el tópico de identificarlo nada más que con un carácter impetuoso y radical ha dado pie a que los juicios emitidos sobre su personalidad sean, del mismo modo, radicales. Ya algunos de sus contemporáneos lo calificaban de "execrable figurón", aunque en la actualidad tampoco se libra de calificativos algo apresurados, como el de "señorito fanfarrón y jactancioso de Jerez" (28) o el de "personaje turbulento y aventurero" (29).

De lo que no cabe duda es de que José Paúl no debe ser exclusivamente recordado o citado a la hora de proponer candidatos para atribuirles el asesinato del general Prim.

\section{APENDICE: TEXTOS}

\section{Texto no1: Intervención de Josê Paúl en favor de la República.}

"El Sr. PAUL Y ANGULO: [...] Hace algunos meses, Sres. Diputados, una reina, hija de cien reyes, y una Constitución liberal, conquista de varias revoluciones, gobernaban a esta Nación. Vosotros y nosotros, el ejército y el pueblo, todos dijimos un día: *abajo lo existente, abajo la dinastía, abajo la Constitución, viva la libertad, viva España con honran y después de muchos siglos de despotismo, después de muchos años de farsa constitucional, España empezó a ser libre, España empezó a ser noble. Hubo un período sublime, hubo un período grandioso en la revolución de Septiembre; pero estuvo reducido a sus primeros momentos. Entonces, Sres. Diputados, jcuánta alegría, cuánto desorden, y al mismo tiempo qué respeto al derecho, qué respeto a la justicia, qué respeto a todo lo noble y a todo lo digno! Pero ya veis, Sres. Diputados, que aquellos momentos desmerecen mucho de los actuales.

Si se hallase presente el Sr. Ministro de Hacienda le diría que en el barómetro de la Bolsa universal podía observar S.S. que no se pare-

(28) C.A.M. Hennessy, La república federal en España. Pi y Margall y el movimiento republicano federal 1868-74. Madrid, Aguilar, 1966, p. 44.

(29) Temma Kaplan, Origenes sociales del anarquismo en Andalucía: capitalismo agrario y lucba de clases en la provincia de Cádiz 1868-1903. Barcelona, Crítica, 1977 , p. 71. 
cen en nada aquellos momentos a los actuales. Y ¿dónde está la causa, Sres. Diputados, dónde está la causa de que la gran aceptación universal de que gozaba la revolución de Septiembre haya desaparecido? Yo creo que es fácil encontrarla. La causa de ese descrédito de la revolución de Septiembre, la causa de que no goce hoy de la misma aceptación que en los primeros momentos, hay que buscarla en los actos del Gobierno provisional, hay que buscarla en los actos del Poder ejecutivo, hay que buscarla en los actos de esta Asamblea, hay que buscarla en ese dualismo que los hombres de la unión liberal, los hombres del partido progresista y los hombres del partido democrático-monárquico han introducido entre el pueblo y los gobernantes, entre el pueblo y el círculo gubernamental, del que ellos y sólo ellos se han apoderado, como su fuesen los verdaderos, los únicos representantes de la revolución de Septiembre.

No me propongo ahora enumerar todos los actos del Poder ejecutivo, todos los actos del Gobierno provisional, todos los actos de la Asamblea Constituyente, que en mi concepto han sido la causa del dualismo que acabo de indicar existe entre una gran parte de los gobernados y los gobernantes. Para probaros que de ese mal sois responsables, basta recordaros cómo se formó el Gobierno provisional, qué hombres lo compusieron y a quiénes se excluyó; basta recordaros después el manifiesto de conciliación, el manifiesto monárquico, en que unos cuantos personajes anteponían su opinión a la del pueblo; recordad después los charcos de sangre, que aún están bien recientes, en las tres ciudades más liberales de Andalucía; recordad la ley humillante del desarme, con pretexto de reorganización, que obligo a aquellos voluntarios a luchar, so pena de aparecer en ridículo ante sus ciudadanos. Seguid más adelante, y recordad la ley votada por las Cortes llamando 25.000 hombres al servicio de las armas por medio de las quintas, desoyendo el grito más sentido y más respetable de la revolución de Septiembre.

[...]

Pues bien, recordad que habéis votado una autorización al Sr. Ministro de Marina concediéndole facultades para llamar 6.000 hombres al servicio marítimo de entre los matriculados de mar; ley que acatando las indicaciones del Sr. Presidente, no calificaré. Recordad también, Sres. Diputados, que hace muy pocos dias habéis votado la sanción de los estados de sitio, completa negación de los derechos individuales: recordad todo lo que yo acabo de enunciar, y decidme después si ese dualismo que existe ahora entre una gran parte de los 
gobernados y los gobernantes es consecuencia de la idea republicana, de esa idea lógica, cuya realización vosotros mismos reconocéis llegará a ser inevitable en España, o si ese dualismo es consecuencia de la idea monárquica, sostenida por medio de la influencia gubernamental, de la idea monárquica, que, en mi concepto, no tiene más defensores que por un lado las bayonetas militares, por otro aquellos a quienes interesa personalmente, y por último, algunos inocentes.

Y yo digo: si el pueblo en las ciudades más populosas de España, en las principales capitales, pide la forma republicana, ipor qué habéis vosotros de desconocer, por qué ha de desconocer el círculo gubernamental, que el elemento republicano debe formar parte de él? Me diréis que es incompatible la idea monárquica con la idea republicana; pero yo os contestaré que si queréis conservar la paz en España, debéis vosotros mismos volveros republicanos para conservar esa paz. ¿Y qué es la monarquía? ¿Qué es esa institución que queréis para España y que os hace arrostrar la impopularidad? ¿Qué es esa institución en defensa de la cụal os exponéis a tener que derramar la sangre de ese pueblo liberal, de ese pueblo que vosotros mismos habéis despertado a la vida política? ¿Qué es la monarquía? Yo he comparado muchas veces la forma monárquica, la existencia de un monarca con un fenómeno de orden físico muy conocido. Tengo comparado al monarca con una masa de gran peso sostenida por tres pies; y creo que así como la masa necesita de esos tres pies para no caer hacia el centro de la tierra, como sucedería si uno de ellos le faltase, así el monarca, ni en España, ni en ninguna otra parte podrá sostenerse sin el apoyo de los sus tres elementos esenciales, que al dar vida a la monarquía empobrecen y deshonran a la Nación: estos tres elementos son la Iglesia, la influencia de la empleomanía, y el militarismo.

No concibo, no comprendo que exista ni pueda existir en el mundo un monarca que no se apoye en la Iglesia; sea la católica, sea la protestante, sea cualquiera otra, con tal que esa Iglesia esté respetada y acatada por la mayoría de la Nación.

¿Y vais vosotros, los hombres de la revolución de Septiembre, a apoyaros en la Iglesia católica, que es esencialmente antiliberal?

Tampoco concibo que exista ni pueda existir en el mundo un monarca que no se apoye en la influencia más o menos grande de los empleados. Y si no, ¿qué habéis tenido que hacer para traer aquí una mayoría monárquica? ¿No es conocido en toda España el trabajo electoral del Gobierno provisional? ¿No sabemos todos que se ha puesto en juego la célebre influencia moral? ¿Y vais a seguir sosteniendo 
semejante inmoralidad para apoyar a vuestro monarca, a ese monarca ridículo? Le llamo así, no seguramente porque lo conozca, sino porque supongo que debe serlo.

Por último, tampoco creo que exista ninguna monarquía que deje de apoyarse en el militarismo. Ved si no esos grandes armamentos que existen en Europa con pretexto de guerras extraordinarias que no llegan a realizarse; armamentos que existen en realidad para defensa de los Gobiernos de las naciones monárquicas, donde el pueblo no manda, pero paga. Vosotros mismos, ino habéis ejercido presión, ni habéis creído necesaria la ley de quintas llamando 25.000 hombres al servicio militar? ¿Qué significa esto, señores? Esto significa que la monarquía no puede sostenerse sin el militarismo; esto significa que la monarquía sin el militarismo, sin la teocracia y sin la empleomanía, no puede resistir a la aspiración del pueblo, no puede resistir a la idea republicana.

Además, Sres. Diputados, conviniendo vosotros conmigo, como no podéis menos de convenir, en que una gran parte del pueblo bracero español es esencialmente republicano; conviniendo vosotros conmigo en que las clases conservadoras, que no se ocupan de política, lo que necesitan es un gobierno estable, un gobierno barato y un gobierno que no debe temer los embates de un partido poderoso, tendréis que convenir también en que hoy lo conservador es la república, en que hoy lo conservador es un gobierno que satisfaga a ese pueblo trabajador y que deje perfectamente tranquilo a ese otro pueblo acomodado y conservador, que lo que desea es la paz.

Que no está preparado el pueblo español para la república. Si decis que vosotros no estáis preparados, si decís que vosotros la rechazáis, necesariamente tengo que convenir en que es verdad porque observo las votaciones. ¡Pero decir que el pueblo en general no está preparado! ¿Pues no hemos observado su conducta desde la revolución de Septiembre acá? ¿Pues en los momentos más críticos no hemos visto al pueblo andaluz, sobre todo, mantenerse perfectamente tranquilo $\sin$ un solo soldado, absolutamente sin guarniciones en las ciudades todas? Decís que el pueblo se ha batido en Cádiz, que se ha batido en Málaga, que se ha batido en Jerez. Ya sabéis, Sres. Diputados, por qué se ha realizado semejante desgracia; ya se ha repetido muchas veces en esta Cámara, y hoy he tenido ocasión de recordarlo. Se han batido los Voluntarios en tres ciudades de Andalucia porque se creyeron rebajados en su dignidad: pero no se han batido con ninguna segunda intención, no existió plan alguno preconcebido. [...] 
Decía que el pueblo español está perfectamente preparado para la república; decía que vosotros, los hombres del Gobierno, podiais no estarlo, podiais rechazarla; pero lo que es el pueblo ha demostrado desde septiembre acá que está completamente en condiciones de ser gobernado por la república.

Y luego, Sres. Diputados, lo más grave del caso es que seguramente ese pueblo que se halla perfectamente dispuesto para la república, no lo está en manera alguna para la monarquía. Yo quiero creer que todos los diputados que nos sentamos en estos bancos vamos a acatar el voto de las Cortes, que todos vamos a respetar lo que la mayoría decida acerca de la forma de gobierno: yo quiero creer que ninguno de nosotros va a estar dispuesto a luchar contra esa forma de gobierno por medio de la conspiración, por medio de la fuerza. Pero también estoy seguro de que el pueblo no hará eso: estoy perfectamente convencido, y porque es una verdad temible la digo para evitar que se realice en su primera y segunda parte, que si votais la monarquía, ahora o dentro de poco seguramente, el pueblo se batirá. [...]

Yo creo lo mismo que el Sr. Ministro de la Guerra: creo que eso es efectivamente cuenta de S.S. Y por lo mismo que es cuenta de S.S., y por lo mismo que yo puedo estar y estoy en posición de saber lo que el pueblo español piensa, y por lo mismo que conviene que S.SS. lo conozcan, por eso pongo en conocimiento de S.SS. lo que yo sé y lo que yo pienso. Yo sentiría muchísimo que se derramase más sangre liberal, y creo que la manera de evitarlo será que antes de votarse el art. 33 aceptéis cualquier forma, la del Directorio, o cualquiera otra si este nombre no os gusta, pero que sea una formula que evite al pueblo español la decepción de ver convertirse en ilusión su grande esperanza.

La forma, señores, que yo propongo en mi enmienda es la del Directorio; y digo en la enmienda que las Cortes Constituyentes y después las ordinarias que se sucedan han de votar cada tres años los cincos individuos que compongan ese Directorio. Esta forma podrá quizás parecer inconveniente, podrá ser excesivo el número cinco, podrá contener cualquier otro detalle en ella que os parezca inconveniente; mas si en el fondo llegáis a aceptar la idea, yo os pido en nombre de la humanidad, en nombre de las víctimas que quizá deban perecer, que hagáis lo posible por conservar algo de la idea que os proponga. He dicho."

(DSCC, 13 de mayo de 1869) 


\section{Texto no 2: Incidente provocado por Paúl y Angulo}

"El Sr. PRESIDENTE: El Sr. Soler tiene la palabra, como uno de los autores, para apoyar la proposición.

El Sr. SOLER (D. Juan Pablo): Sr. Presidente, creo que el Sr. Paúl y Angulo, mi compañero, había presentado antes que yo otra proposición. Si así fuera, desearía que se le concediera la palabra para apoyarla, y si no, estoy dispuesto a apoyar la mía.

El Sr. PRESIDENTE: Las proposiciones se han presentado al mismo tiempo, y la Mesa está en el derecho de dar lectura de ellas como lo crea conveniente.

El Sr. PAUL Y ANGULO: Pido la palabra para rectificar un error del Sr. Presidente.

El Sr. PRESIDENTE: Su señoría no tiene el derecho de rectificar ningün error del Presidente.

EI Sr. PAUL Y ANGULO: Las proposiciones las he presentado yo mismo.

El Sr. PRESIDENTE: Usia ha entregado las dos proposiciones al mismo tiempo, y el Presidente tiene el derecho de fijar el orden de lectura.

El Sr. PAUL Y ANGULO: Pues que conste que la mía fue la primera.

El Sr. PRESIDENTE: No puede hacerse constar nada tratándose de un derecho de la Mesa.

El Sr. PAUL Y ANGULO: ¡Pero si yo mismo he entregado a S.S. una y otra en su despacho, diciendo: uestas dos proposiciones vengo a entregar: la mia es la primera, y la segunda es esta, que me ha dado el señor Solern!

El Sr. PRESIDENTE: Usía no tiene derecho a fijar cuál es la primera ni la segunda; las dos se han entregado a la vez, y el Presidente ha mandado que se diera lectura de ellas como lo ha creído conveniente.

El Sr. PAUL Y ANGULO: Pero tengo derecho para hacer constar que la mía fue la primera.

El Sr. PRESIDENTE: Su señoría no está en el uso de la palabra.

El Sr. PAUL Y ANGULO: Pero tengo el derecho de hacer constar...

El Sr. PRESIDENTE: Su señoría no tiene derecho para hacer constar nada.

El Sr. PAUL Y ANGULO: Creo tenerle para hacer constar que mi proposición es la primera presentada.

El Sr. PRESIDENTE: Señor Paúl, yo sentiría mucho, y siento por el pronto, empezar los debates de la tercera legislatura como S.S. Ios quiere inaugurar. 
El Sr. PAUL Y ANGULO: No es mía la culpa si así empiezan.

El Sr. PRESIDENTE: Señor Paúl, no me obligue su señoría a que use de los derechos que me concede el Reglamento.

El Sr. Soler tiene la palabra para apoyar su proposición.

(El SR. Paúl y Angulo abandona su asiento y se retira del salón cubriéndose antes de salir. Varios Sres. Diputados reclaman el uso de la palabra y protestan contra este acto. Momentos de agitación.)

El Sr. PRESIDENTE: Ruego a los Sres. Diputados que ocupen sus asientos. (Sigue la efervescencia.)

El Sr. FIGUERAS: Lo que yo pido a los Sres. Diputados es que no apliquen a las cuestiones de decoro de la Cámara la pasión de partido, que todo lo pervierte. (Rumores.)

El Sr. PRESIDENTE: Señor Figueras, Sres. Diputados, atendido el acto de descortesía que el Sr. Paúl y Angulo ha tenido para con sus compañeros en particular, para con la Cámara reunida, y para con el que tiene la honra de presidirla, el Congreso, después de terminada la sesión pública, se reunirá en secreta, con arreglo al Reglamento, para que acuerde lo que crea conveniente a su decoro. (Muestras de aprobación.)

El Sr. PAUL Y ANGULO (que ba vuelto a ocupar su asiento): Pido la palabra, Sr. Presidente.

El Sr. PRESIDENTE: No hay palabra Sr. Paúl.

El Sr. PAUL Y ANGULO: Para dar una explicación inmediata.

El Sr. PRESIDENTE: Tiene S.S. la palabra para explicar el porqué se ha cubierto antes de salir del salón.

El Sr. PAUL Y ANGULO: Señores Diputados, yo creo que todos vosotros habréis observado, puesto que habéis hecho cierto ruido al tiempo de cubrirme yo, habréis observado, digo, que lo he hecho fuera ya de la escalera donde están los asientos de los Sres. Diputados; y yo creo que el cubrirse un metro antes o un metro después de llegar a la puerta, nada absolutamente significa. (Murmullos, protestas en diversos sentidos.)

Cuando yo quiera decir una verdad a las Cortes Constituyentes, no me valdré del sombrero. He dicho.

El Sr. PRESIDENTE: Su señoría se guardará muy bien con el sombrero o sin él, no de hacerlo, sino de intentar siquiera nada que pueda rebajar el decoro de la Cámara Constituyente.

Queda terminado este incidente.

El Sr. PAUL Y ANGULO: Diré verdades, Sr. Presidente; nada más que verdades.

El Sr. PRESIDENTE: Ha concluido este incidente. Yo siento mucho no poder decir a S.S., porque respeto a la Cámara y me respeto a mí mismo, todo lo que yo siento acerca de este particular. 
El Sr. Soler tiene la palabra para apoyar su proposición.

El Sr. SOLER (D. Juan Pablo): Sres. Diputados, la minoría republicana acude a las Cortes Constituyentes... (El Sr. Paúl y Angulo se retira del salón llevando en alto el sombrero. Nuevos rumores.)

El Sr. PRESIDENTE: Suplico a los Sres. Diputados que guarden silencio. El Sr. Soler tiene la palabra."

(DSCC, 31 de octubre de 1870) 